\title{
PROVENANCE AND THE LIMINALITY OF PRODUCTION AND CONSUMPTION: THE CASE OF WINE PROMOTERS
}

\author{
Jennifer Smith Maguire \\ Citation: \\ 2010. Marketing Theory. 10(3): 269-82. \\ Author contact: jbs7@le.ac.uk
}

\begin{abstract}
Cultural intermediaries actively mediate between production and consumption: they operate at the interfaces between and within firms, and between firms and customers, and reflexively negotiate between their roles as symbolic producers and taste-leading consumers. The article examines the liminality of cultural intermediaries through a case study of wine promoters, using the theme of provenance as an empirical lens through which to examine both their work in creating added-value for particular wines, and their identities as reflexive producer/consumers. In its distinctive account of boundary work in practice, the article contributes to emerging research on the subjectivity of market practitioners - a crucial perspective on the relationship between production and consumption, but one which has yet to be fully developed in marketing theory and its discussions of value co-creation and the prosumer.
\end{abstract}

\section{Keywords}

consumption; cultural intermediaries; mediation; production; provenance; wine

\section{Introduction}

Growing attention in the social sciences is directed at the character and significance of the service class and, in particular, 'cultural intermediary' occupations responsible for the production and legitimation of various images, experiences, identities, and lifestyles (e.g. Bourdieu, 1984; du Gay, 2004; du Gay and Pryke, 2002; Nixon and du Gay, 2002). Cultural intermediaries occupy boundary-spanning positions (Wharton, 1999), operating at the interfaces between and within firms, and between firms and customers; they are thus implicated in the day-to-day processes of representing brands, brokering relationships and shaping experiences. Less tangibly but no less significantly, cultural intermediaries also operate at the boundary between the social categories of production and consumption, reflexively negotiating between their roles as symbolic producers of added-value, and high-involvement, taste-leading consumers. Existing research has positioned cultural intermediaries as liminal figures, mediating between production and consumption (e.g. Cronin, 2004; Entwistle, 2006; Smith Maguire, 2008; Wright, 2005). However, the active accomplishment of their liminality - and associated constructions of economic value and occupational identity-remains largely unexplored in the field of marketing studies. 
This article examines the liminality of cultural intermediaries through a case study of wine promoters, including wine makers, publicists, retailers, distributors, and writers. The emphasis, here, is on how the promoters' narratives about their work practices and personal preferences reveal the ongoing and potentially ambivalent negotiations that occur between their various positions within the field of wine. The article thus offers a distinctive account of boundary work in practice: how identities and categories emerge out of the 'betwixt and between' (Turner, 1995: 95) of production and consumption. As part of emerging research on the subjectivity and 'inside view' of market practitioners (Cook, 2006), the article contributes a crucial perspective on the relationship between production and consumption, which has yet to be fully developed in discussions of 'value co-creation' (e.g. Prahalad and Ramaswamy, 2000), and the 'prosumer.' Like prosumers, who contribute (unpaid) creative and affective labour to the creation of value (e.g. Tapscott and Williams, 2007), cultural intermediaries are reflexive producer/consumers for whom the market and culture are inseparable (Slater, 2002); unlike prosumers, cultural intermediaries draw on their cultural capital and affective capacities to do their paid work of making calculations about - and ideally better managing - the reflexivity of other consumers (cf. Moor, 2008; Soar, 2000). To study cultural intermediaries is thus to study key agents charged with the 'governmental' mobilization of consumers (Miller and Rose, 1997; Zwick et al., 2008).

The analysis focuses on wine promoters' various conceptualizations and mobilizations of provenance with regard both to their work as symbolic producers on behalf of particular wines, and to their identities as reflexive producer/consumers. Provenance is a logical choice for an empirical lens through which to explore wine promoters' producing and consuming narratives. Origin-based quality claims are well-established for food and wine (cf. Amilien and Holt, 2007; Thode and Maskulka, 1998). Traditionally for wine, this takes the form of terroir: the contention that wines reflect the local, physical conditions (climate, topography, soil) of production. However, this traditionalist view of terroir-as a trait intrinsic to agricultural products - is increasingly challenged in the wine market by strategic constructions of provenance - as a marketing tool encompassing notions of cultural and regional heritage, personality and authenticity (Charters, 2006; Vaudour, 2002). Past research on the marketing of wine through provenance has typically focused on producers' branding strategies (e.g. Beverland, 2005) or consumers' understandings (e.g. Tustin and Lockshin, 2001); the roles of the cultural intermediaries who bridge these two realms remain largely unexplored.

Furthermore, provenance is a timely issue, related to ongoing discussions of the market value of origins, authenticity and heritage (e.g. Kirschenblatt-Gimblett, 1998; Peñaloza, 2000; Peterson, 2005; Zukin, forthcoming). Economic value is being extracted from constructions of provenance in an increasing range of consumer fields well beyond those of food and wine, from place branding for cities and countries (e.g. Morgan et al., 2001), to the use of accountable supply chains to distinguish fashion goods (Moor and Littler, 2008; Sinopoli and Verner, 2008), and the use of assembly location to imbue products such as automobiles with an authentic essence (anon., 2007). Thus, how the issue of 'where things come from' is framed and understood by wine promoters can shed light, 
more broadly, on processes of value construction and the attitudes of a niche of highinvolvement consumers.

The article proceeds with an overview of the literature on cultural intermediaries, highlighting the foundation provided by Pierre Bourdieu (1984), and more recent 'cultural economy' (du Gay and Pryke, 2002) case studies of such occupations, which share a concern with the ways in which the boundaries between culture and economy are accomplished. Following a description of the methods used in the research, the discussion then turns to the different ways in which provenance was articulated in the wine promoters' narratives, relative to their roles as symbolic producers and reflexive producer/consumers.

\section{Cultural Intermediaries}

Bourdieu typically serves as the starting point for research on cultural intermediaries. In Distinction (1984), Bourdieu draws on large-scale survey data of French consumers' preferences and behaviours from the late 1960s and early 1970s to explore social class as a crucible for shaping tastes and practices, and the role of consumption in processes of social differentiation. Of particular interest are the new petite bourgeoisie, whose social position and the interplay between their stocks of economic and cultural capital give rise to an ethos of self-investment and self-presentation, and a conspicuous affinity for consumer culture. Exemplars of the new petite bourgeoisie are the cultural intermediaries, working in:

occupations involving presentation and representation (sales, marketing, advertising, public relations, fashion, decoration and so forth) and in all the institutions providing symbolic goods and services. These include the various jobs in medical and social assistance... and in cultural production and organization (Bourdieu, 1984: 359).

Of note are the ways in which the new petite bourgeoisie are involved not only in the production but also legitimation of cultural goods - for it is through such validation that they hope to consolidate their own social position, relative to (and against) the established dominant, middle and working classes. Legitimacy, however, takes a different form than that wielded by the established dominant class and their occupations. Rather than the binding authority of the state or the rational authority of traditional professions such as medicine and law, cultural intermediaries employ embodied capital and subjective knowledge - e.g. physical appearances, aesthetic attitudes, leisure practices - to legitimate their advice and influence over others.

Cultural intermediaries are regarded as significant in the social dynamics of markets because of their personal and professional investments in the cultural goods and services they promote. They produce symbolic added-value by disseminating, and converting others to, their belief in consumer goods and services as legitimate markers of social status and repositories of cultural value. It is this proselytizing aspect of their work that leads Bourdieu (1984: 365) and others to suggest that cultural intermediaries act as the 'transmission belt' of a new consumer morality, and the lynchpin for a post-Fordist consumer culture and service economy (e.g. Florida, 2002; Lash and Urry, 1994). 
Tempering such grand claims is a growing body of empirical research on how cultural intermediaries are implicated in the mutual constitution of production and consumption in fields such as advertising and branding (Cronin, 2004; McFall, 2004; Moor, 2008; Soar, 2000); magazine publishing (Crewe, 2003); book retailing (Wright, 2005); and fashion (Entwistle, 2006; Pettinger, 2004; Skov, 2002). Often falling under the banner of 'cultural economy' (du Gay and Pryke, 2002), such work understands economy and culture as dynamic and mutually iterative categories. Cultural economic analyses draw from the anthropology of science and techniques (AST), actor-network theory (ANT) and Foucault's work on governmentality (McFall, 2004: 63, 82-3) to indicate 'the ways in which objects and persons are constituted through the discourses and techniques used to describe them and to act upon them' (du Gay, 2004: 100). Such a perspective rejects the notion of a contemporary blurring or hybridization of boundaries, as it posits a radical break from an earlier era of static categories; instead, the pertinent question is how the boundaries between categories such as 'economy' and 'culture,' 'production' and 'consumption' (among others) are accomplished, dialectically, through specific, material practices.

As such, this research regards production and consumption as having a liminal relationship. To describe production and consumption as liminal is to insist on an area of 'active mediation' (Aguirre, Quance and Sutton, 2000: 30) between the two, in which individuals engage in practices, construct narratives and employ dispositions that place the realms in dialogue (in such a way that may be (mis)diagnosed as a 'new' blurring of boundaries), while at the same time accomplishing a division between them (Latour, 1993). Anthropological discussions frame liminality as a portal to and conduit for the experience of communitas - the shared, spontaneous social bond that exists in the interstitial spaces of the conventional social structure (Turner, 1995: 129). Such experiences of connectedness - with and through products - are understood as powerful generators of value in critical marketing discussions of value co-creation (Arvidsson, 2005). Therein lies the importance of the cultural intermediaries, who draw upon their simultaneous position as symbolic producers and high-involvement consumers in order to engineer experiences of communitas for other consumers. If the liminal spaces and 'betwixt and between' (Turner, 1995: 95) figures were typically outside of a tribal society's everyday status order, they are, now, increasingly central to it: the hippie's marginal status has made him or her a coveted 'cool hunter' in today's 'hip' marketplace (Frank, 1997).

Hence, the empirical interest in cultural intermediaries as liminal personae, actively mediating between production and consumption, forging opportunities for connectedness, meaning and value out of such mediations. Their liminality is not simply a matter of mediating, objectively, between producers of material products and their end consumers, but also, subjectively, between their roles as producers and consumers. Their subjective preferences and personal lifestyle form a crucial occupational resource - a fount of expert knowledge, bestowing legitimacy on cultural intermediaries' goods or services, and on their authority as arbiters of taste and style. Cultural intermediaries are thus understood as reflexive producer/consumers, for whom categories such as work and leisure seem to overlap. Consider, for example, the role of physique, apparel and sexuality in 
demonstrating the occupational competence and credibility for, respectively, personal trainers (Smith Maguire, 2008), fashion retail assistants (Pettinger, 2004), and 'gay market' marketing professionals (Sender, 2004). The crux of the matter is not that work and leisure, production and consumption overlap (which, in itself, is unremarkable), but how cultural intermediaries work within that space of overlapping to forge occupational identities, market boundaries and symbolic value.

\section{Studying Wine Promoters}

The article is based on qualitative interview research (Alford, 1998) with a sample of 27 individuals involved in shaping and promoting the premium wine market. In terms of their primary occupational roles, 9 work as publicists or marketers/marketing consultants; 8 as winemakers or winemaking consultants; 5 as sommeliers, restaurateurs and/or retailers; 3 as distributors/importers; and 2 as wine writers. All are involved - to greater and lesser degrees, with more and less intentionality - in the promotion of wine, be it increasing the visibility, legitimacy, market value or perceived quality of specific wines, wineries, or wine in general. Furthermore, the respondents all interact with small-scale wineries on a professional level, working (rarely exclusively) with boutique wineries or wines. This is significant regarding the theme of provenance, as small-scale wine brands often have production elements (e.g. a single vineyard or a family-owned and -run operation) that mark them as different from the large-scale brands against which they compete, and which may be more likely to yield resonant - and lucrative - meanings of origin, authenticity, and so forth.

The research included two types of interviews, conducted in the spring of 2007 in two major Australian cities. Eight interviews (R1-8) were conducted at a trade event for wineries; these 'flash' interviews (cf. Chapman, 1999) lasted 5 to 15 minutes and involved an informal discussion about the particular wine brand. The remainder of the respondents, recruited from personal contacts and snowball sampling, participated in semi-standardized interviews (12 in person; 7 via the telephone), following a two-part question guide with the expectation of probing for further detail: what do you do in your work to add value to wine?; as a consumer, how would you describe your wine preferences? Responses to the first question about work practices reflected standard practices for the construction of brand identities, such as designing logos, packaging and other promotional material, securing endorsements and high-status affiliations, and managing consumers' experiences. Responses to the second question, similarly, reflected common conventions for assessing wine quality (Charters and Pettigrew, 2006), both in terms of objective qualities such as a wine's typicity (especially common for highinvolvement drinkers), and relative to other criteria such as price point and situation.

As much as a cultural economic framework may recognize production and consumption as intertwined in practice, the research design thus performed a separation, explicitly asking respondents to 'change hats' between thinking of themselves as producers or consumers. This was further reflected in the thematic analysis of the interview transcripts. A priori templates of codes (Crabtree and Miller, 1999; King, 2004) for analysing the data were derived from the literature on cultural intermediaries and their dual roles as symbolic producers and connoisseur consumers; in particular, deductive coding revolved 
around the themes of adding and assessing value. These findings were then refined through an iterative process that generated data-driven inductive findings (Fereday and Muir-Cochrane, 2006), including the concept of provenance. The analysis thus adopts an interpretive stance: wine promoters are regarded as market actors whose experiences, perceptions and narratives contribute to the ongoing, problematic and potentially contested constitution of occupational identities and cultural categories such as "the market.' The article proceeds from the premise that the market exists only as a cultural practice (e.g. McFall, 2004; Slater, 1993). The interviews are thus treated not as transparent reflections on occupational and leisure practices, but as active moments of self-production and cultural-production: a narrativizing of both the self (Giddens, 1991) and the boundaries between production and consumption.

\section{Research Findings}

Provenance was a broad meta-theme cutting across respondents' producing and consuming narratives, incorporating such elements as origin, heritage and context of production with reference to the wine, winemaker and/or vineyard, as well as personal experience or specialized knowledge of such elements. As a general concern with 'where things come from,' provenance is a fluid category through which respondents can be understood as symbolic producers, mediating between wines and the market, and as reflexive producer/consumers, mediating between their occupational and leisure roles and identities. It is along these two lines that the following discussion of findings is structured.

\section{Wine Promoters as Symbolic Producers}

Cultural intermediaries utilize their knowledge of, and access to, forms of legitimate culture in order to embed products in particular contexts and embed within them particular meanings (Moor, 2008). Provenance was one strategic means (among others) used by wine promoters to try to mediate the context of production and the experience of consumption, and thus increase a wine's marketability and market value. For example, the following respondent (R3: female), responsible for sales and promotions for a New Zealand winery run by a French winemaker, highlights the importance of the label:

The first year, [the winemaker] had chosen this awful label with flowers on it. I convinced them to go with [our current label], which is more 'Old World.' Clearly we're New World wine, but with the old label it was too much New World.

Echoing the winemaker's heritage, the wine's new label uses château-esque imagery, signalling a difference from other New Zealand wineries, which typically feature traditional/Maori imagery. For R3, the advantage is clear: at a Singapore wine event, 'they went straight for our table, and pretty much ignored the other New Zealand wines that were there, because they recognize that the name is French, and they equate that with quality.' Thus, the strategic use of the established credibility of French culture helps to symbolically situate and augment the product.

The name of the product is also crucial in setting a wine apart from competitors. For example, the following respondent (R15: male) - a renowned winemaker of premium pinot noir-reflects on the importance of the name and the story it tells: 
I spent six years agonizing over the name, trying to find a name with two words that sounded punchy enough and related to where I was. I looked at names of mountains and the quirky names like 'my brother's left foot', and finally came to the names of two famous explorers in the region. And the name was an immediate success. It wasn't long after launching that people were using the name, asking for it.

The responses from R3 and R15 highlight the obstacles (and opportunities) faced by New World wines, which may lack an established reputation (for the winemaker, region, or both). One solution to this dilemma - the 'quirky name' - explicitly rejects tradition, signalling a wine's style not in terms of variety or region but lifestyle. For the majority of the respondents in this research, however, product stories tended to be provenance stories: origin myths that embed the product in a particular context of creation by selectively framing aspects of its production, such as the winemaker's biography or the history of the region. As a narrative construct, provenance stories have a considerably looser relationship than terroir with the actual conditions of production. For example, a popular Australian brand's strapline, 'Welcome to our place,' evokes a local identity for a product that is, in fact, made from grapes sourced from across South Australia: a symbolic re-territorialization of a diffuse production system (cf. Lury, 2004: 54). Anathema to terroir purists, such narratives of provenance nevertheless resonate with the broader use of heritage as a source of value for cultural products.

Constructions of provenance are used to manage the impressions and experiences of consumers, be it through labels, displays, reviews or-most immediately-the performative labour of a wine promoter. For example, the following respondent (R9: male), now owner of a wine management company, reflects on his strategy of employing sommeliers as retailers when he previously managed the boutique wine shop of a luxury hotel:

Sommeliers are passionate about what they're doing. And that's fantastic. And that ultimately drives the consumer. The consumer knows, 'I'm getting something right to drink. And I've got the story behind it.' So when I set up the wine shop, I wanted the shop run by sommeliers, because a sommelier will get intimately involved in what they are serving. And they will show and tell the story. And at the end of the day, you as a consumer will pick up that bottle and you will go home and you will tell the story to your friends. 'Do you know that the guy who made this wine...'

Constructions of provenance occur at a variety of levels of immediacy, from standardized labels to interpersonal performances. As such, many of the respondents (particularly marketers and distributors who mediate between winemakers and retailers) provided educational services, training staff so 'that the wine becomes alive' (R14: male; distributor), and thereby enabling other actors in the circuit of culture to serve as performers of provenance.

Similarly, the following respondent (R26: male), the global marketing director for a national wine industry organization, highlights the importance of narrative for legitimating the product: 
When you have a lot of small producers, and when you're selling at that premium or super-premium end of the market, then it's all about the stories. It's all about knowing something about the wine. 'This is from a tiny winery, overlooking the sea.' It's about the personal stories. And it's those stories that sell the 6 to 8 pound bottles of wine. For the $£ 3.90$ bottle of wine, for the 3 for 2 offers on the Australian wine: it's cheap and it's boring. But for the 6 pound bottle, you can say, 'I was at this wine fair, and I met this great winemaker...'

As for nearly all the respondents, R9 and R26 position the 'average' consumer as less knowledgeable, and reliant on the wine promoter to establish particular wines as 'worthy choices' (Johnston and Baumann, 2007: 170). Provenance stories not only set wines apart from each other, but also offer consumers cultural capital (the story) as added-value. Hence, the importance of the cultural intermediary: the product is enhanced by the provenance story, but the perceived sincerity (Beverland, 2005) - and value — of that story rests on the cultural authority of the wine promoter. Wine promoters accomplish the 'production of the value of the work or, what amounts to the same thing, of the belief in the value of the work' (Bourdieu, 1996: 229).

Wine promoters make cultural and economic calculations - what is included, what is left out-in the types of stories they tell and the selective transparency (Lury, 2004: 161) they offer: a partial view of some aspects of the conditions of production (the vineyard's charms, the winemaker's quixotic dreams) that disguises or ignores other aspects (the day-to-day financial realities of making wine). Wines are thereby embedded in a particularized, personalized and fictional context of production, increasing consumers' trust in, and willingness to pay a premium for, the product (Sassatelli and Scott, 2001). As 'invented traditions' (Hobsbawm and Ranger, 1983), provenance stories mediate between the actual material production of a wine and its reception in the marketplace (cf. Jack and Phipps, 2005: 55).

By contextualizing the product (cf. Johnston and Baumann, 2007: 178), wine promoters provide consumers with a personal stake in a wine's 'back story,' and a potential entrée to an experience of communitas (the romanticized conviviality of winemaking) or membership (the rarefied cadre of wine insiders). This pedagogical aspect of wine promotion, however, has the awkward consequence of demystifying the object on which claims to professional authority rest. Or, as Wright (2005: 111) observes of cultural intermediaries in the book trade: 'They are torn between winning a market for cultural goods, which entails popularization, and preserving the rarity and difference that is the essence of their social position and power.' For wine promoters, as for cultural intermediaries more broadly, it is a matter of livelihood to insist that there is a gap between production and consumption, between themselves and the average consumer-a gap they are uniquely able to bridge (Cronin, 2004; Entwistle, 2006). The study of wine promoters thus contributes a nuanced view of the 'enduring distance' between production and consumption (Negus, 2002). The contemporary era of the prosumer is not about finally overcoming this distance in order to seamlessly incorporate the consumer, but about selectively mediating the distance, giving access to some but not all of the 'inside view' of provenance in order to indirectly manage the consumer's experience of connectedness with the product. As a mechanism for embedding products, the 
provenance story is itself a liminal product, the outcome of wine promoters' reflexive identities as producer/consumers.

\section{Wine Promoters as Reflexive Producer/Consumers}

Cultural intermediaries 'always sell themselves as models and as guarantors of the value of their products' (Bourdieu, 1984: 365). The implication for wine promoters is that the consumption of wine is not only a matter of personal interest and preference, but also, unlike for other wine drinkers, a matter of livelihood. The relationship between occupational practices and consuming preferences can take various forms, including drinking in order to know the market and 'benchmark your product' (R18: female; publicist), and mobilizing personal consuming choices as emblems of professional credibility. In both respects, wine promoters are exemplars of the reflexive producer/consumer, who employs a capacity to reflect and draw on occupational and leisure experiences in order to inform future practices. In short: they rely on the personal to accomplish the professional (Smith Maguire, 2008). With regard to provenance, such reflexivity tends to revolve around particular stocks of cultural and social capital.

For example, asked to describe his consuming preferences, the global marketing director for a national wine industry organization (R26) explains his personal taste with reference to knowledge:

People in the wine industry love pinot noir, because it's the toughest grape to grow. It's the toughest to blend. It's got thin skins, it's a fickle grape, and it needs a lot of love and attention and you can taste that in the glass. Pinot noir is the holy grail for winemakers. And for white wine, it's probably riesling. Riesling shows its place, and it requires a lot of winemaking skills. You know, [some] winemakers will get sniffy about sauvignon blanc, they'll say it's too easy. You just grow it and squeeze it.

Bourdieu's (1984) work suggests that taste is less a matter of the preferred object per se than the reason behind the preference. Broadly speaking, he identifies a class-based pattern in tastes for the popular and functional (for the working class), or the esoteric and luxurious (for the bourgeoisie). A preference for an esoteric wine may thus shift if the wine becomes popular or 'too easy' - as when sauvignon blanc replaces chardonnay as the top-selling wine (Port, 2009). If taste is an expression of cultural capital, and social status is established through differentials in forms of capital, then the proselytizing aspects of wine promotion raise unintended consequences: converting others to the object of your taste diminishes the exclusivity of that wine, stimulating the search for new varietals (such as riesling) that can signal the difference between the wine promoter and the 'average' consumer.

Key to establishing distance from the average consumer - a distinction on which occupational status and professional credibility rest-is the wine promoter's stock of cultural capital (e.g. specialized oenological knowledge and the embodied capital of palate) and social capital (e.g. personal relationships with winemakers and other wine promoters). These resources are explicitly put into practice - and on display - through personal consumption choices. Therein lies the utility of provenance goods as positional goods. In the contemporary status economy, as access to formerly exclusive cultural 
knowledge has widened, the possession of such knowledge is not enough. Status now requires the active and conspicuous display of knowledge (Skeggs, 2001: 148): not just choosing the riesling over the sauvignon blanc, but also performing its story.

Wine promoters' reflexivity as producer/consumers hinges on the source and deployment of capital. Their stock of knowledge about wine is drawn from both leisure and work experiences (indeed, many attributed their broad range of experiences to both personal interest and the nature of their work, through which they have had access to wines otherwise beyond their reach); and that knowledge is used to both assess their options as wine consumers, and legitimate their authority as wine promoters. For example, consider the following comment from the wine management company owner (R9: male) comparing two wines of the same grape variety:

I bought Hill of Grace, which I still probably consider today a better wine than Grange, and I consider it so because Hill of Grace comes from the vineyard Hill of Grace, in Eden Valley, in the Barossa Range, in Barossa. It's made by a couple, Stephen and Prue Henschke, and it is what you get. Classifying Hill of Grace (small-scale) as better than Penfolds Grange (global luxury wine brand), R9 simultaneously classifies himself as a credible intermediary, whose palate and knowledge of provenance mean that he is not swayed by brand reputation. The precondition of wine promoters' social and occupational position is the ability to adopt a tactical position relative to branding and promotional strategies. Like R9, several respondents criticized the market value of Grange as a product of 'hype.' Similarly, in discussions of blind tasting (where the promotional context is removed and tasters are reliant solely on palate), respondents often noted with pride that their preferences were not necessarily the wines with the most awards or highest prices. Wine promoters' consuming practices must convincingly demonstrate their 'good' taste for some forms of provenance over others, thereby creating a critical distance between themselves and the market.

A preference for small-scale wineries was common across respondents, and their comments echoed existing research on the association of authenticity with the handcrafted, local, non-commercial, natural and traditional as opposed to the mass-produced and industrialized (e.g. Johnston and Baumann, 2007; Sassatelli and Scott, 2001; Zukin, forthcoming). The issue of provenance, here, brings into focus the tension between the large- and small-scale, the industrialized and artisanal, the inauthentic and authentic. Neither static nor inherent, such terms are discursively accomplished through the ongoing exercise of dispositions and practices. For example, consider how R17 (female), who organizes wine events as part of her work as public relations director of a luxury hotel, describes her preference for small-scale wines:

It's like anything: if you wear a dress which was designed by someone that you met you feel closer to it; if you buy a painting from an artist that you've met, or you have your house decorated by someone that you've met... I think that people just like to have connections with the people with whom they do transactions. ...People really want to feel that they have a connection, so they have wine in the fridge that they can pull out and say to friends, 'Oh I met the winemaker and he 
was delightful,' or, you know, 'He was an irascible character,' or whatever it may be.

Similarly, the owner of an upscale restaurant with an extensive Old World wine list (R20: male) explains his preferences with reference to heritage- - his own and that of winemaking generally:

I think the New World are like green winemakers, and the Old World are brown winemakers. I'm using that as a metaphor, green meaning clean, technical, stainless steel, very structured; brown meaning chickens running around the vineyards, sort of rustic. What has happened with the green style winemaking, we've become so green, that our wines in Australia are suffering this homogenized effect. In my perspective and having an Italian background, it's simple: food, wine, and earnest conversation. ... So, [the Old World] is incredibly romantic to me. ... It's age-old, and it's been there forever, so there's this beautiful romanticism.

Like R17 and R20, many of the wine promoters espoused the belief that (some) wine still holds the possibility of an authentic experience, unmediated by advertising, labels and the like - what Turner (1995) might describe as communitas. The roots of this romantic notion of wine lie in its long history as a social drink, the uses of which cross temporal, cultural and class boundaries (Charters, 2006), and in its agricultural context, which is more pronounced for small-scale producers, and especially those employing biodynamic principles where the rationality, calculability and predictability (Ritzer, 1996) of largescale mass producers is absent, or at least severely curtailed by the changing patterns of climate.

Research on fields such as advertising (Soar, 2000) and branding consultancy (Moor, 2008) suggests that cultural intermediaries use themselves as proxies for their intended consumer market. For R17 and R20 - as for the wine promoters generally - their status as reflexive producer/consumers implies that these personal preferences (for the small-scale, hand-crafted and that which is perceived as authentic) impact on the choices they make for which wines to bring to market (through selection for a wine event, wine list and so forth), and the strategies they adopt to affiliate those wines with the perceived aspirations and desires of the target market. Tangible, firsthand experiences of provenance, however, remain largely the preserve of the few, who can then trade on such forms of cultural and social capital. By translating personal experience into provenance stories, wine promoters serve as liminal conduits for a strategically constructed, mediated form of communitas, from which economic value (occupational success for the wine promoter; market value for the wine) can be extracted (cf. Arvidsson, 2005).

\section{Conclusion}

Wine promoters operate in the liminal space between production and consumption. Drawing on personal dispositions and experiences, they construct added-value through contextualizing devices and narratives. At the same time, wine promoters in their consuming narratives located the value of wine outside of economic parameters, as something authentic and convivial, exempt from the manipulations of the marketincluding those to which they had actively contributed. The wine promoters' ambivalent relationship with the market is thus captured in the concept of provenance: it may be 
understood as both a strategic device for adding value, which aligns them with an economic agenda; and as a tactical device for assessing value, which distances them from the average consumer and aligns them with a small-scale, 'authentic' and less commercial culture of production (cf. de Certeau, 1984). In their narratives, wine promoters thus place these realms in dialogue while insisting on their separation, thereby implicating them in the ongoing reproduction of the categories of, and the distance between, production and consumption.

Since the mid $20^{\text {th }}$ century, marketing has increasingly concerned itself with how best to overcome this distance between production and consumption, by affiliating product qualities and brand values with consumers' perceived desires and anxieties. In this way, marketing has developed as a governmental technology directed at 'mobilizing' (Miller and Rose, 1997; see also Zwick et al., 2008) consumers to enact their freedom within the marketplace in appropriate ways, and thereby (ideally) accomplishing a seamless flow between supply and demand. However, consumer markets have continued to fragment and tastes to change, meaning that the gap between producers and consumers remains as 'one of the most vexing barriers toward increasing control over markets' (Zwick et al., 2008: 182). Recent discussions of value co-creation through drawing the consumer (or prosumer) into the production process (e.g. Arvidsson, 2005; Prahalad and Ramaswamy, 2000; Tapscott and Williams, 2007) are examples of attempts to overcome this barrier.

However, these 'solutions' do not remove the distance between production and consumption; rather, they reassert and mediate the distance in strategic ways. The figure of the prosumers implies - and requires - that of the reflexive producer/consumer: the market actor who draws on his or her own subjective preferences and experiences to produce an empathetic assessment, and effective management, of the interests and ingenuity of others.

Stepping back from the specific case of wine promoters, the study of cultural intermediaries thus offers to marketing theory, more broadly, a crucial-but not, as yet, fully explored - perspective on the subjective dynamics of markets: how the affective capacities and cultural capital of service workers serves as the basis for value creation, via the engineering of affective opportunities and paths for consumers (and prosumers). The governmental mobilization of consumers' freedom and economic exploitation of prosumers' creative labour and emotional attachment require a cadre of intermediaries who finesse those linkages between the realms of production and consumption. This underlines the importance of problematizing market(ing) practitioners. Further research on such occupations is necessary to grasp how various actors attempt to channel consumers' freedom along prescribed routes by affiliating their perceived fears and aspirations with particular product qualities. Who better to do such work than those whose liminal status affords them a view of both sides of the equation?

\section{Acknowledgements}

Thanks to those editors and reviewers who offered constructive suggestions on an earlier draft. 


\section{References}

Aguirre, M. Quance, R. and Sutton, P. (eds.) (2000) Margins and Thresholds: An Enquiry Into the Concept of Liminality in Text Studies. Madrid: Gateway Press.

Alford, R. (1998) The Craft of Inquiry: Theories, Methods, Evidence. New York: Oxford University Press.

Amilien, V. and Holt, G. (eds.) (2007) Special Issue on Local Food Products and Systems. Anthropology of Food S2 (March). http://aof.revues.org/sommaire34.html. Accessed January 2008.

Anon. (2007) 'UK: NAC trumpets return of MG to Longbridge', Just-Auto. Accessed online (http://www.just-auto.com/article.aspx?ID=91466), May 2007.

Arvidsson, A. (2005) 'Brands: A Critical Perspective', Journal of Consumer Culture $5(2): 235-58$.

Beverland, M.B. (2005) 'Crafting Brand Authenticity: The Case of Luxury Wines', Journal of Management Studies 42(5): 1003-29.

Bourdieu, P. (1984) Distinction: A Social Critique of the Judgment of Taste. Cambridge, MA: Harvard University Press.

Bourdieu, P. (1996) The Rules of Art. Cambridge: Polity Press.

Chapman, T. (1999) 'The Ideal Home Exhibition: An Analysis of Constraints and Conventions in Consumer Choice in British Homes,' in J. Hearn and S. Roseneil (eds.) Consuming Cultures: Power and Resistance, pp. 69-90. Basingstoke: Macmillan.

Charters, S. (2006) Wine \& Society: The Social and Cultural Context of a Drink. Oxford: Elsevier.

Charters, S. and Pettigrew, S. (2006) 'Conceptualizing Product Quality: The Case of Wine', Marketing Theory 6(4): 467-83.

Cook, D. (2006) 'In Pursuit of the 'Inside View': Training the Research Gaze on Advertising and Market Practitioners', in R.W. Belk (ed.) Handbook of Qualitative Research Methods in Marketing, pp. 534-46. Cheltenham: Edward Elgar Publishing.

Crabtree, B. and Miller, W. (1999) 'Using Codes and Code Manuals: A Template Organizing Style of Interpretation', in B. Crabtree and W. Miller (eds.) Doing Qualitative Research, $2^{\text {nd }}$ ed., pp. 163-77. Thousand Oaks, CA: Sage.

Crewe, B. (2003) Representing Men: Cultural Production and Producers in the Men's Magazine Market. Oxford: Berg.

Cronin, A. (2004) 'Regimes of Mediation: Advertising Practitioners as Cultural Intermediaries?', Consumption, Markets and Culture 7(4): 349-69.

de Certeau, M. (1984) The Practice of Everyday Life. Berkeley : University of California Press.

du Gay, P. (2004) 'Devices and Dispositions: Promoting Consumption', Consumption, Markets and Culture 7(2): 99-105.

du Gay, P. and Pryke, M. (eds.) (2002) Cultural Economy: Cultural Analysis and Commercial Life. London: Sage.

Entwistle, J. (2006) 'The Cultural Economy of Fashion Buying', Current Sociology 54: 704-24.

Fereday, J. and Muir-Cochrane, E. (2006) 'Demonstrating Rigor Using Thematic Analysis: A Hybrid Approach of Inductive and Deductive Coding and Theme Development', International Journal of Qualitative Methods 5(1): 1-11. 
Florida, R. (2002) The Rise of the Creative Class. New York: Basic Books.

Frank, T. (1997) The Conquest of Cool: Business Culture, Counterculture and the Rise of Hip Consumerism. Chicago: University of Chicago Press.

Giddens, A. (1991) Modernity and Self-Identity: Self and Society in the Late Modern Age. Cambridge: Polity.

Hobsbawn, E. and Ranger, T. (eds.) (1983) The Invention of Tradition. Cambridge: Cambridge University Press.

Jack, G. and Phipps, A. (2005) Tourism and Intercultural Exchange: Why Tourism Matters. Clevedon: Channel View.

Johnston, J. and Baumann, S. (2007) 'Democracy Versus Distinction: A Study of Omnivorousness in Gourmet Food Writing', American Journal of Sociology 113(1): 165-204.

King, N. (2004) 'Using Templates in the Thematic Analysis of Text', in C. Cassell and G. Symon (eds.) Essential Guide to Qualitative Methods in Organizational Research, pp. 256-70. London: Sage.

Kirschenblatt-Gimblett, B. (1998) Destination Culture: Tourism, Museums, and Heritage. Berkeley: University of California Press.

Lash, S. and Urry, J. (1994) Economies of Signs and Space. London: Sage.

Latour, B. (1993) We Have Never Been Modern. New York: Harvester Wheatsheaf.

Lury, C. (2004) Brands: The Logos of the Global Economy. London: Routledge.

McFall, L. (2004) Advertising: A Cultural Economy. London: Sage.

Miller, P. and Rose, N. (1997) 'Mobilizing the Consumer: Assembling the Subject of Consumption', Theory, Culture \& Society 14(1): 1-36.

Moor, L. (2008) 'Branding Consultants as Cultural Intermediaries', The Sociological Review 56(3): 408-28.

Moor, L. and Littler, J. (2008) 'Fourth Worlds and Neo-Fordism: American Apparel and the Cultural Economy of Consumer Anxiety', Cultural Studies 22(5): 700-23.

Morgan, N., Pritchard, A. and Pride, R. (eds.) (2001) Destination Branding: Creating the Unique Destination Proposition. Oxford: Butterworth-Heinemann.

Negus, K. (2002) 'The Work of Cultural Intermediaries and the Enduring Distance Between Production and Consumption', Cultural Studies 16(4): 501-15.

Nixon, S. and du Gay, P. (2002) 'Who Needs Cultural Intermediaries?', Cultural Studies 16(4): 495-500.

Peñaloza, L. (2000) 'The Commodification of the American West: Marketers' Production of Cultural Meanings at the Trade Show', Journal of Marketing 64(October): 82-109.

Peterson, R.A. (2005) 'In Search of Authenticity', Journal of Management Studies 42(5): 1083-98.

Pettinger, L. (2004) 'Brand Culture and Branded Workers: Service Work and Aesthetic Labour in Fashion Retail', Consumption, Markets and Culture 7(2): 165-84.

Port, J. (2009) 'Sav Blanc Downs Chardy as Leading White', The Age (Melbourne), 25 January. Accessed online (http://www.theage.com.au/articles/2009/01/24/1232471659714.html), March 2009.

Prahalad, C.K. and Ramaswamy, V. (2000) 'Co-opting Customer Competence', Harvard Business Review 78(January/February): 79-87. 
Ritzer, G. (1996). The McDonaldization of Society: An Investigation into the Changing Character of Contemporary Social Life. Rev. ed. Thousand Oaks, CA: Pine Forge Press.

Sassatelli, R. and Scott, A. (2001) 'Novel Food, New Markets and Trust Regimes: Responses to the Erosion of Consumers' Confidence in Austria, Italy and the UK', European Societies 3(2): 213-44.

Sender, K. (2004) Business, Not Politics: The Making of the Gay Market. New York: Columbia University Press.

Sinopoli, D. and Verner, A. (2008) 'Picks and Pans', Globe and Mail 27 December, L7.

Skeggs, B. (2001) Class, Self, Culture. London: Routledge.

Skov, L. (2002) 'Hong Kong Fashion Designers as Cultural Intermediaries: Out of Global Garment Production', Cultural Studies 16(4): 553-569.

Slater D. (1993) 'Going Shopping: Markets, Crowds and Consumption', in C. Jenks (ed.) Cultural Reproduction, pp. 188-209. London: Routledge.

Slater, D. (2002) 'Capturing Markets From the Economists', in P. du Gay and M. Pryke (eds.) Cultural Economy, pp. 59-77. London: Sage.

Smith Maguire, J. (2008) 'The Personal is Professional: Personal Trainers as a Case Study of Cultural Intermediaries', International Journal of Cultural Studies 11(2): 203-221.

Soar, M. (2000) 'Encoding Advertisements: Ideology and Meaning in Advertising Production', Mass Communication \& Society 3(4): 415-37.

Tapscott, D. and Williams, A.D. (2007) Wikinomics: How Mass Collaboration Changes Everything. New York: Penguin.

Thode, S.F. and Maskulka, J.M. (1998) 'Place-based Marketing Strategies, Brand Equity and Vineyard Evaluation', Journal of Product \& Brand Management 7(5): 379-99.

Turner, V. (1995) The Ritual Process: Structure and Anti-Structure. New York: Aldine de Gruyter.

Tustin, M. and Lockshin, L. (2001) 'Region of Origin: Does It Really Count?', Australian and New Zealand Wine Industry Journal 16(5): 139-43.

Vaudour, E. (2002) 'The Quality of Grapes and Wine in Relation to Geography: Notions of Terroir at Various Scales', Journal of Wine Research 13(2): 117-41.

Wharton, A.S. (1999) 'The Psychosocial Consequences of Emotional Labor', The Annals of the American Academy of Political Social Science 561: 158-76.

Wright, D. (2005) 'Mediating Production and Consumption: Cultural Capital and "Cultural Workers", British Journal of Sociology 56(1): 105-21.

Zukin, S. (forthcoming) Naked City. New York: Oxford University Press.

Zwick, D., Bonsu, S.K. and Darmody, A. (2008) 'Putting Consumers to Work: 'Cocreation' and New Marketing Govern-mentality', Journal of Consumer Culture 8(2): 163-96. 